\title{
Off-pump coronary artery bypass (OPCAB) in complex coronary artery bypass procedures - a report of four cases and review of the literature
}

\section{David G. Harris and Jacques T. Janson}

Department of Cardiothoracic Surgery, Tygerberg Hospital, University of Stellenbosch, South Africa

Address for correspondence:

Dr D. G. Harris

Kuils River Hospital

PO Box 1200

Kuils River

7579

Email:

drdharris@yahoo.co.uk

ABSTRACT Off-pump coronary artery bypass (OPCAB) surgery is a procedure that is still not widely used by all cardiac surgeons. In the USA about $20-25 \%$ of coronary artery bypass graft (CABG) surgery is done offpump. Current literature suggests that both OPCAB and CABG with cardiopulmonary bypass have similar mortality rates, but OPCAB surgery does offer less morbidity, and advantages in terms of mortality and stroke rates in certain high risk patients.

We discuss the role of OPCAB surgery in high risk patients, especially redo operations through a left thoracotomy to protect an intact internal mammary artery (LIMA) graft to the left anterior descending artery (LAD) and in patients with a calcified ascending aorta. Four case reports are used as examples and the literature is reviewed, which shows a superior outcome with OPCAB surgery in these complicated cases. SAHeart 2008; 5:82-87

\section{INTRODUCTION}

Off-pump coronary artery bypass (OPCAB) surgery is still a controversial issue. The main controversy is whether or not $O P C A B$ surgery is more beneficial for the patient compared to on-pump surgery.
OPCAB surgery is not a new development, having been pioneered by the Russian surgeon Dr Kolesov, in the 1960s. He performed over 100 cases in this way, using the internal mammary artery, sometimes bilaterally. ${ }^{(1)}$ At the same time aorto-coronary bypass was being pioneered with the use of cardiopulmonary bypass, but Kolesov felt that this was unnecessary. The use of cardiopulmonary bypass allowed anastomoses to be performed easily, with a bloodless vessel and acceptable mortality and morbidity.

In the 1980s Benetti from Argentina reported over 700 cases of single vessel, off-pump procedures, where the internal mammary was anastomosed to the LAD. ${ }^{(2)}$ Long-term follow-up in these patients has shown equivalent graft patency.

This sparked off a revival of the procedure and, with the advent of new stabilizers and other advances such as intracoronary shunts and atomizer spray devices, allowing a more bloodless field, the technique has flourished. According to recent data from the Society for Thoracic Surgeons database, OPCAB accounts for just $23 \%$ of all isolated bypass procedures performed in the United States. ${ }^{(3)}$ There is, however, a large discrepancy between different units, where some do over $50 \%$ of cases off-pump while many other units do virtually none. ${ }^{(4)}$

For a new procedure or technique to be adopted into practice, it has to fulfil 3 criteria: the procedure must have proven benefit for the patient, it must be user friendly and there must be effective education of the user. ${ }^{(4)}$ Many surgeons already comfortable and familiar with conventional techniques are unwilling to change to techniques that are still evolving. This is understandable, because OPCAB surgery does have a learning curve ${ }^{(5)}$ and many on-pump surgeons feel they would compromise on completeness and accuracy of revascularization and patient outcome during this learning curve.

Avoiding cardiopulmonary bypass has the obvious advantage of avoiding its harmful effects, such as pulmonary, renal and cerebral dysfunction, coagulopathy and depressed cellular and humoral immunity - all attributal to the systemic inflammatory response caused by 
extracorporeal blood circulation through abnormal artificial surfaces. The short-term benefits are less myocardial injury (myocardial enzyme release, as well as low cardiac output), less blood utilization and reoperation for bleeding, shorter time to extubation and less prolonged ventilation, less renal dysfunction, less sternal infection, shorter hospital stay and decreased hospital cost. ${ }^{(6)}$

When comparing major outcomes such as mortality, stroke, myocardial infarction and renal failure, the difference in on and off-pump surgery is less clear. Many studies have failed to show statistically significant differences. A meta-analysis of 37 randomized trials of OPCAB versus conventional $C A B G$ showed no statistical difference in these events. ${ }^{(7,8)}$

In an attempt to shed more light on outcome, Mack and his colleagues pooled data from 4 centres experienced in off-pump surgery. From I7 40 I patients they were able to match II 458 patients by a computerized propensity score into on and off-pump groups..$^{(9)}$ Variables used were gender, renal failure, hypertension, previous CVA, congestive heart failure, chronic lung disease, cerebrovascular disease, redo surgery, left main disease and surgical priority. The off-pump group showed a lower mortality $(2.0$ vs. $3.7 \% \mathrm{p}<0.0 \mathrm{I})$ and stroke rate $(\mathrm{I} .4 \mathrm{vs}$. $2.1 \% p<0.01$ ). Furthermore, the off-pump group experienced no increased incidence of any complication compared with the on-pump group. The authors noted that OPCAB was particularly beneficial for patients older than 75 , for women and for redo operations.

Another even larger propensity score matched study with data from the STS National Cardiac Database matched 17696 pairs of patients into on and off-pump surgery groups. They also found a survival benefit for off-pump surgery, with most benefit seen in patients older than 66, females, patients with poor left ventricular function, diabetics and redo operations. ${ }^{(10)}$

Perioperative stroke is a devastating complication and has a risk of $1 \%$ to $5 \%$. In patients older than 80 years this can be as high as 10\%.(1) The causes are multifactorial. Aortic manipulation can dislodge atheroma, microemboli from the bypass circuit could embolize to the brain and perioperative arrythmias could also be a source of emboli.

Risk factors for stroke are patients older than 70 years, diabetes, peripheral vascular disease, unstable angina and atheromatous disease of the ascending aorta. ${ }^{(12)}$ Two studies compared off and on-pump surgery in patients older than 70 and 75 years respectively. Both studies found a significant reduction in the stroke rate in off-pump patients. . $^{(13,14)}$ Another study compared off and on-pump patients with atheromatous ascending aortas. ${ }^{(15)}$ There were 212 patients in each group. The stroke rate $(2.5 \%$ vs. $4.7 \% p=0.08)$ and the mortality rate were significantly reduced in the off-pump group ( $3.8 \%$ vs. $11.4 \% \mathrm{p}=0.003)$.
We report four cases as examples where we believe OPCAB is the best option, and where the literature has demonstrated a superior outcome in these complicated cases.

Reoperation with intact internal mammary artery (LIMA) to left anterior descending artery (LAD) anastomosis.

A thoracotomy is performed, avoiding risk of injury to patent LIMA to LAD anastomosis (Figure I).

\section{Case I}

A 60-year-old male patient, who had undergone coronary bypass grafting 3 years previously (LIMA to LAD) presented with an acute inferolateral non q-wave myocardial infarction.

The patient developed severe post-infarction angina and ischemic pulmonary edema.

Cardiac catheterization revealed a left ventricular ejection fraction of approximately $30 \%$.

There was minimal mitral regurgitation present. The left main coronary artery was completely occluded. The right coronary artery was small and diffusely diseased. The LIMA to LAD anastomosis was still patent, the circumflex completely occluded and the obtuse marginals could be

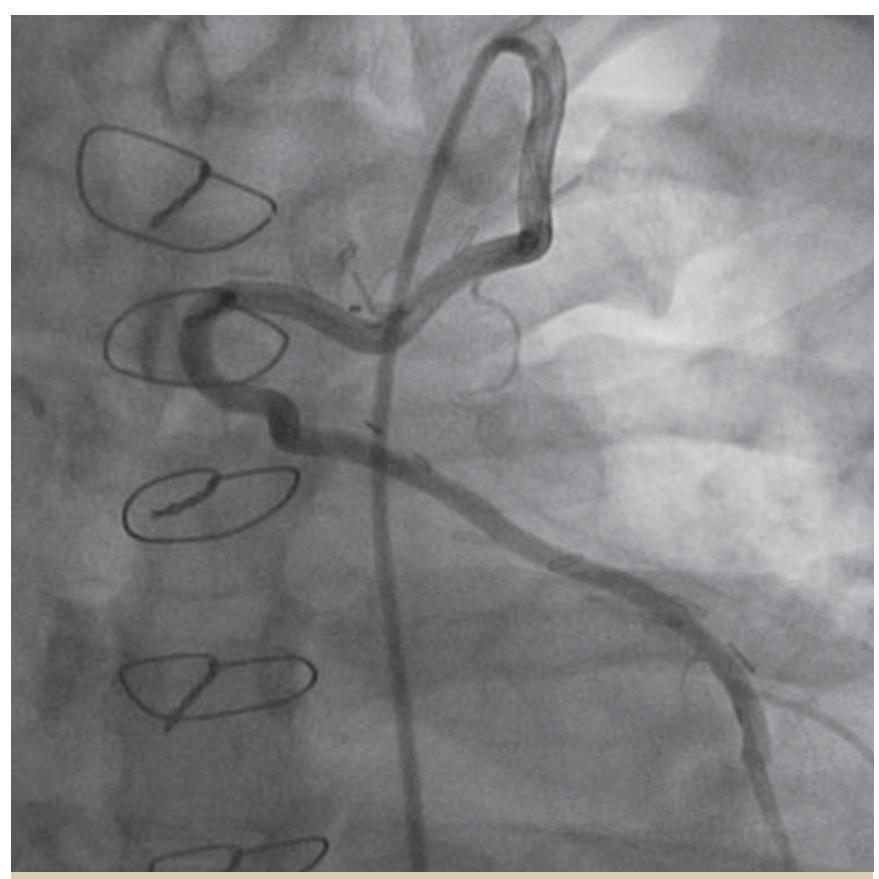

FIGURE I: Intact internal mammary (LIMA) graft to LAD. Note how the vessel crosses to the midline. The lateral view (not shown) confirmed contact with the posterior sternum - with almost certain risk of injury with reoperation. 
seen filling from retrograde via the LAD. The second obtuse marginal appeared to be a good vessel for grafting.

An intra-aortic balloon pump was inserted and a low-dose dobutamine infusion was started.

A left lateral thoracotomy incision was performed.

The second obtuse marginal was easily visualized, and the area around the vessel was immobilized using a suction tissue stabilizer. The vessel was opened, and was of good quality, measuring $1.75 \mathrm{~mm}$. It was revascularized with a saphenous vein, which was grafted to the descending aorta (Figure 2).

There was no cardiac instability during the procedure. The patient made a full recovery without any complications, and remains free from angina. Three years after the second operation, he underwent cardiac catheterization for atypical chest pain. This confirmed both the LAD and circumflex grafts to be patent. Eight years has elapsed since the second operation, and he remains symptom free.

\section{Case 2}

A 58-year-old male patient who had undergone coronary bypass II years previously presented with significant angina, which was responding poorly to medical therapy. Cardiac catheterization revealed

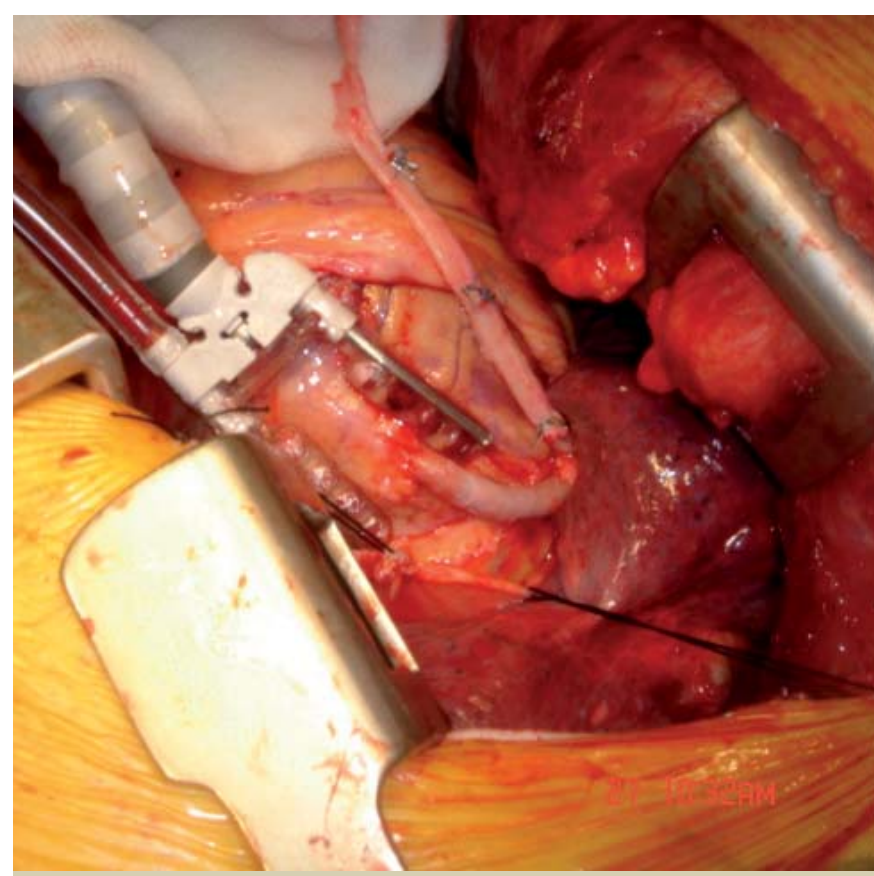

FIGURE 2: Intra-operative detail of repeat CABG via left thoracotomy. Note the excellent exposure of the circumflex artery. It is much more accessible with this approach than a sternotomy, and this is the ideal approach for single (or multiple) grafts to the lateral wall. good left ventricular function. The LIMA to LAD anastomosis was intact, but was adherent to the back of the sternum, and crossing the midline, making injury during sternotomy likely (Figure I). The right coronary artery was diffusely diseased, small and ungraftable. The saphenous vein graft to the third obtuse marginal vessel was occluded, and the native vessel was small. The vein graft to the second obtuse marginal had a significant stenosis at the anastomosis site, and the native vessel was of good quality. The stenotic graft site was stented; however, the patient only had transient relief from his symptoms, and again presented with intolerable angina, despite adequate medical therapy. Repeat coronary angiogram revealed in-stent stenosis.

A left lateral thoracotomy was performed and, simultaneously, the right radial artery was harvested.

The second obtuse marginal was identified, immobilized with the tissue stabilizer and was grafted with the radial artery from the descending aorta.

The patient recovered without complications and has no angina after 6 years follow-up.

A repeat angiogram was recently performed, during performance of another vascular procedure, and this confirmed patency of the graft (Figure 3).

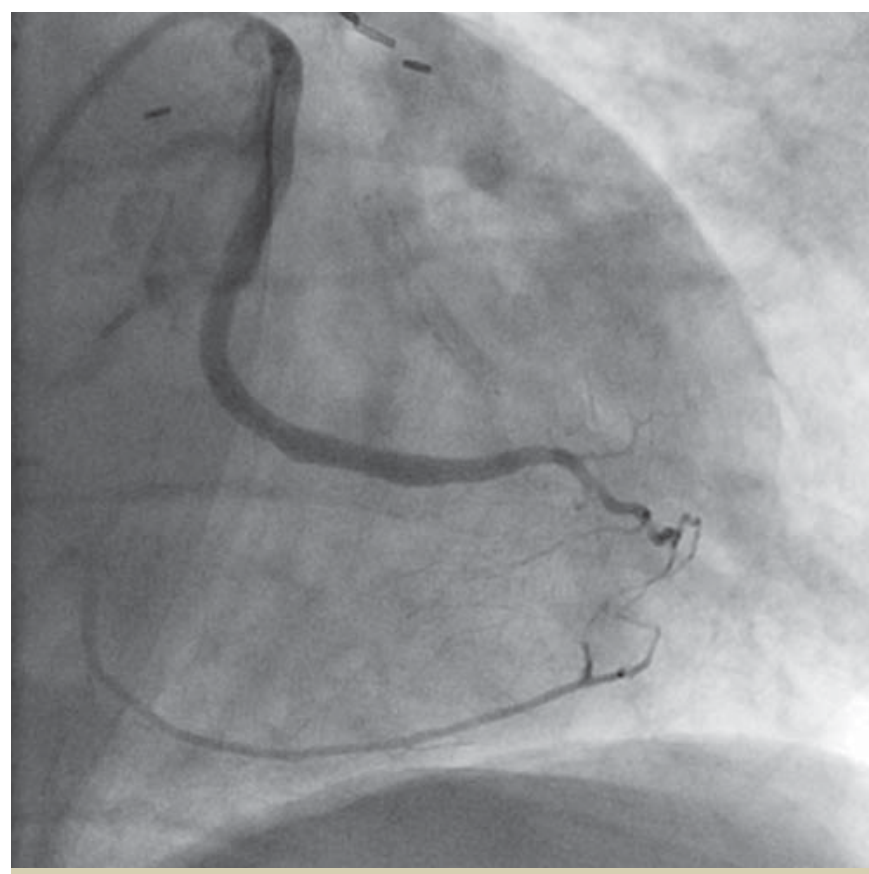

FIGURE 3: Repeat angiogram revealing patent graft from descending aorta to second marginal branch. The vessel lies in a gentle curve formation, directly from the descending aorta, without any kinking. 


\section{Diffusely calcified (“porcelain”) ascending aorta}

This condition is often diagnosed only after opening the chest and palpating the aorta. In the past this was usually considered to be an inoperable condition, as clamping the aorta would have an almost certain risk of stroke.

\section{Case 3}

This 67-year-old obese female patient presented with unstable angina. Cardiac catheterization revealed a completely occluded LAD (that filled from collaterals), and severe proximal stenoses of the second obtuse marginal of circumflex and right coronary artery. She was presented for triple vessel bypass.

Median sternotomy revealed a diffusely calcified ascending aorta, which was impossible to cannulate and clamp.

The heart was hypertrophied, but the target vessels easily visualized, so the patient was considered for a beating heart procedure.

The left internal mammary artery was dissected out. The LAD was brought into view by retracting on sutures placed into the left posterior pericardium. The vessel was immobilized with the tissue stabilizer, opened, and bleeding controlled by snaring the vessel with a proximal stitch. The vessel was easily visualized, with conditions similar to that with cardiopulmonary bypass, and was grafted with the LIMA. Saphenous vein grafts were then performed from the innominate artery (which was non-calcified) to the right coronary artery and the second obtuse marginal.

Specific techniques were used to expose the heart, without any hemodynamic compromise, but details of these techniques are beyond the scope of this article.

Full revascularization was achieved without having to touch the aorta. The patient made an uneventful recovery.

\section{Case 4}

This 79-year-old female patient presented with unstable angina, which was responding poorly to medical treatment. Cardiac catheterization revealed moderately depressed ventricular function. The LAD and second obtuse marginal vessels had critical proximal stenoses.

The right coronary had a critical lesion just before its bifurcation. Supraaortic injection revealed a calcified ascending aorta.
Median sternotomy was performed and the diffusely calcified ascending aorta was confirmed. Both internal mammary arteries were dissected out and were excellent vessels.

Using the same techniques as in Case 3, the left IMA was grafted onto the LAD, and the right IMA onto the right coronary before its bifurcation. The circumflex vessel was grafted with saphenous vein, which had been grafted to the innominate artery. Once again, it was not necessary to touch the diffusely calcified aorta. The patient made an uneventful recovery.

\section{Discussion}

The profile of the CABG patient has changed in the last $10-15$ years. Patients referred for surgery are older and often have more comorbidities. Efforts to reduce mortality and morbidity have been focused on better myocardial protection, reduction of cerebral embolization, arterial grafts, better peri-operative care and off-pump surgery.

From the literature there is evidence that patients with the following risk factors have a better outcome with off-pump surgery: $(6,9,10,16,17)$

Elderly (>70years)

- Chronic lung disease

- Renal insufficiency

- Calcified ascending aorta

- Cerebrovascular disease

- Women

- Redo operations

- Poor left ventricular function

Bleeding diatheses

- Diabetics

With current techniques it is possible to do most isolated coronary bypass operations off-pump, although the following are less suitable: cardiomegaly (CT ratio>0.7); left ventricular hypertrophy; ischemic mitral regurgitation; calcified, intramyocardial and small coronary vessels. Whether these patients can be done off-pump depends on the surgeon's experience in off-pump surgery. ${ }^{(16)}$

We believe that patients with an intact LIMA to LAD anastomosis requiring repeat lateral wall revascularization can be more safely operated on the beating heart via a left thoracotomy. The mortality of a repeat sternotomy in this setting ranges from $6.9-11.5 \% .{ }^{(17)}$ If a patent LIMA to LAD anostomosis is injured during re-operation, the mortality can be up to $50 \% .{ }^{(18)}$ The thoracotomy approach has a reported near zero mortality in small series. ${ }^{(19,20)}$ 
The thoracotomy approach for the repeat operations is not a new approach, despite limited published articles. D'ancona et al. used this approach first in 1971, using femoral cannulation and cardiopulmonary bypass. Since then they have performed 59 re-operations this way, mostly off-pump. ${ }^{(21)}$ Other researchers during the 1980s used the left thoracotomy approach, but using femoro-femoral bypass. ${ }^{(22,23)}$

Left thoracotomy OPCAB for redo procedures was used as early as 1993, when Fanning reported 49 patients and a mortality of 3.4\%.(24) They and other authors conclude it is the method of choice for repeat CABG when marginal branches are the only targets. ${ }^{(18,19)}$ We currently have a series of 55 patients, with a mortality rate of $1.8 \%$ (I patient).

Patients with a diffusely calcified "porcelain" aorta present a challenging problem to the cardiologist and surgeon. The calcium usually extends into the coronary ostia, making stenting impossible. The condition is usually recognized on the angiogram, but often the diagnosis is only made after opening the chest. In the past, surgeons would usually declare the patient inoperable and close the chest because manipulation of the aorta has a significant risk of causing a stroke. Presently most surgeons would at least do a LIMA to LAD graft off-pump, and ask the cardiologist to stent the ungrafted vessels.

It is important to recognize the calcified aorta pre-operatively and perform a CT scan to assess the extent of the calcification. This may allow better planning of further management.

Other methods have been used in patients with a calcified ascending aorta. Alternative cannulation sites can be used for cardiopulmonary bypass, such as the axillary, ${ }^{(25)}$ or femoral artery. ${ }^{(26)}$ The distal anastomoses can be performed after inducing ventricular fibrillation and the proximal conduit is grafted onto a softer spot on the aorta during a brief period of circulatory arrest. (27) This procedure has high morbidity, especially in older patients with comorbidities. An alternative is the use of bilateral internal mammary arteries with the patient supported on femoral bypass and the grafts done on the beating heart. ${ }^{(26,27)}$ This avoids having to place any grafts on the ascending aorta. Recently there have been reports of OPCAB surgery without touching the aorta and in this patient group the stroke rate is significantly reduced. ${ }^{(15)}$ Another alternative is combining LIMA to LAD OPCAB with percutaneous revascularisation of other vessels. ${ }^{(28)}$

The long-term results of OPCAB surgery still need to be conclusively evaluated. We need to compare late mortality, reintervention rate, graft patency and late cardiac events. There is one earlier report of increased re-interventions after multiple vessel OPCAB (seven-year follow up), ${ }^{(29)}$ but this was before the more recent technologic advances mentioned above.
Calafiore has demonstrated equivalent graft patency in the short and medium term. ${ }^{(30)}$ Puskas et al. were able to place a substantially higher number of grafts per patient (3.2 per patient for $O P C A B$ and 3.4 for on-pump) than most of the earlier trials. They found I-year graft patency rates in both OPCAB (94\%) and on-pump (96\%) to be similar $(p=0.34) .{ }^{(3)}$ Sabik and colleagues found equivalent mid-term outcomes (4-year follow-up) between on and off-pump patients, which included freedom of death, all coronary reinterventions and myocardial infarction. ${ }^{(32)}$ It will be very interesting to follow the long-term results of these studies over the next few years.

\section{CONCLUSION}

Off-pump surgery is a useful tool in the surgeons' armamentarium, especially to manage certain high risk patients, since a superior outcome can be expected for this patient group. It should be mastered with the same technical precision as on-pump surgery without compromising the quality of the graft anastomosis. Each patient's surgical treatment option must be carefully tailored according to the patient's need and the surgeon's experience. 


\section{REFERENCES:}

I. Kolessov VI. Mammary artery-coronary artery anastomosis as method of treatment for angina pectoris. JThorac Cardiovasc Surg 1967; 54:535-44

2. Benetti FJ, Naselli G, Wood M, Geffner L. Direct myocardial revascularization without extracorporeal circulation.Experience in 700 patients. Chest. 1991; 100(2):312-6.

3. Petersen ED, Mark DB. Off-pump Bypass Surgery - Ready for the Big Dance? JAMA. 2004; 291:1897-1899.

4. Mack MJ. Off-pump Cardiac Surgery. Semin Thorac Cardiovasc Surg 2003; 15(I):44.

5. Ferguson TB Jr, Shroyer AL, Coombs LP, DeLong ER, Grover FL, Peterson ED. Riskadjusted mortality, revasularization completeness and the learning curve effect in offpump CABG. Circulation 2003; 108:IV-391.

6. Connelly M. Current results of off-pump coronary artery bypass surgery. Semin Thorac Cardiovasc Surg 2003; I (1):45-51.

7. Cheng DC, Bainbridge D, Martin JE, Novich RJ, Evidence Based Perioperative Clinical Outcome Research Group. Does off-pump coronary artery bypass reduce mortality, morbidity, and resource utilization when compared with conventional coronary artery bypass? A meta-analysis of randomized trials. Anesthesiology 2005; 102 (1): 188-203.

8. Wijeysundera DN, Beattie WS, Daiani G. Off-pump coronary artery surgery for reducing mortality and morbidity: meta-analysis of randomized and observational studies. J Am Coll Cardiol 2005; 46(5):872-82.

9. Mack MJ, Phister A, Bachard D, et al. Comparison of coronary bypass surgery with and without cardiopulmonary bypass in patients with multivessel disease. J. Thorac Cardiovasc Surg 2004; 127:167-73.

10. Magee MJ, Coombs LP, Petersen ED, Mack MJ. Patient selection and current practice for off-pump coronary artery bypass surgery. Circulation 2003; 108: ||9-||| 4.

I I. Stamou SC, Hill PC, Dangas G, et al. Stroke after coronary artery bypass: Incidence, predictors, and clinical outcome. Stroke 200 I; 32:1508-1513.

12. Newman MF, Wolman R, Kanchger M, et al. Multicenter preoperative stroke risk index for patients undergoing coronary artery bypass graft surgery. Multicenter Study of Perioperative Ischemia (McSPI) Research Group. Circulation 1996; 94(9 Suppl): 1174-80.

13. Ricci M, Karamanoukian HC, Dancona G, et al. On-pump and off-pump coronary artery bypass grafting in the elderly: Predictors of adverse outcome, J Cardiovasc Surg 200 I; 16:458-466.

14. Hirose H, Amano A, Takahashi A, Off-pump coronary artery bypass grafting for elderly patients. Ann Thorac Surg 200 I; 72:2013-2019.

15. Sharony R, Bizekis CS, Kanchuger M, et al. Off-pump coronary artery bypass grafting reduces mortality and stroke in patients with atheromatous aortas: a case control study. Circulation 2003; 108 Suppl 1:|l| 15-20.

16. Lancey R. Off-pump coronary artery bypass surgery. Curr Probl Surg 2003; 40(I I): 693-802.

17. Lytle BW. Coronary Artery Reoperations. In: Cohn LH, Edmunds LH Jr, eds. Cardiac Surgery in the Adult. New York: McGraw-Hill 2003; 659-679.

18. Baumgartner F, Gheissari A, Panagiotides G, et al. Off-pump obtuse marginal grafting with local stabilization: thoracotomy approach in reoperations. Ann Thorac Surg 1999; 68: 946-8.

19. Fouad M, Azoury A, Gillinov M, et al. Off-pump reoperative coronary artery bypass grafting by thoracotomy: patient selection and operative technique. Ann Thorac Surg 2001; 71:1959-1963.

20. Azoury FM, Gillinov AM, Lytle BW, Smedira NG, Sabik JK. Catastrophic Hemorrhage during redo sternotomy. Ann Thorac Surg 1984; 37:273-8.

21. Azoury FM, Gillinov AM, Lytle BW, Smedira NG and Sabik JK. Thoracotomy approach in reoperations. Ann Thorac Surg 2000; 69:971-82.

22. Burlingame MW, Bonchek LI, Vazales BE. Left thoracotomy for reoperative coronary bypass. JThorac Cardiovasc Surg 1988; 95(3):508-510.

23. Randolph Bolton, JW. Left thoracotomy for reoperative revascularization of the posterior coronary circulation. J Cardiovasc Surg (Torino); 38(4):407-4I 0.

24. Fanning WJ, Kakos GS, Williams TE Jr. Reoperative coronary artery bypass grafting without cardiopulmonary bypass. Ann Thorac Surgery; 55:486-489.
25. Leyh RG, Bartels C, Notzold A, Sievers HH. Management of porcelain aorta during coronary artery bypass grafting. Ann Thorac Surg 1999; 67(4):986-8.

26. Olearchyk AS. Calcified Ascending Aorta and Coronary Artery Disease. Ann Thorac Surg 1995; 59:1013-5.

27. Akpinar B, Gunden M, Sanisoglu I, Konuralp C, Yilmaz O, Sonmez B. A no-touch technique for calcified ascending aorta during coronary artery surgery. Tex Heart Inst J 1998; 25(2): 120-3.

28. Gaudino M, Cellini C, Bruno P, Zimarino M, Possati G. Integrated approach for revascularization in multivessel coronary artery disease and porcelain aorta. J Card Surg 1998; 13(2): 140-2.

29. Gundry SR, Romano MA, Shattuck OH, Razzouk AJ, Bailey LL. Seven-year follow-up of coronary artery bypasses performed with and without cardiopulmonary bypass. J.Thorac. cardiovasc. Surg 1998; I I5(6): I273-7.

30. Calafiore AM, Teodori G, Di Giammarco G, et al. Multiple arterial conduits without cardiopulmonary bypass: early angiographic results. Ann Thorac Surg 1999; 67:450-456.

31. Puskas JD, Williams WH, Mahoney EM, et al. Off-pump vs. conventional coronary artery bypass grafting: early and I-year graft patency, cost, and quality-of-life outcomes: a randomized trial. JAMA 2004; 291: 1841- 849

32. SabikJF, Blackstone EH, Lytle BW, Houghtaling PL, Gillinov AM, Cosgrove DM. Equivalent midterm outcomes after off-pump and on-pump coronary surgery. J.Thorac Cardiovasc Surg 2004; 127:142-8 